\title{
DENSITY FUNCTIONAL THEORY STUDIES ON IR SPECTRA OF THE TRIPHENYLENE DERIVATIVES. A SCALED QUANTUM MECHANICAL FORCE FIELD APPROACH
}

\author{
K. Merkel, A. Kocot, R. Wrzalik and B. Orgasińska \\ Institute of Physics, University of Silesia, Uniwersytecka 4, 40-007 Katowice, Poland
}

Density functional theory, B3-LYP with the $6-31 \mathrm{G}^{*}$ basis set was applied to study the structures and vibrational infrared spectra of triphenylene and the hexasubstituted triphenylene derivatives. The calculated force fields were scaled using the scaled quantum mechanical force field method. The predicted vibrational frequencies were compared with the experimental IR spectra $\left(500-4000 \mathrm{~cm}^{-1}\right)$. The spectra were interpreted and vibrational assignments were reported. This study shows that the scaled density functional force field approach enables, through the transferability of scale factors, good interpretation of vibrational spectra of large molecules.

PACS numbers: $61.30 .-\mathrm{v}, 78.30 . \mathrm{Jw}, 31.15 . \mathrm{Ew}$

\section{Introduction}

Molecules forming discotic columnar and discotic nematic phases generally consist of a rigid planar core with four to eight flexible aliphatic tails. The structural features associated with both the flexible chain and the rigid core are of the great importance for understanding the mesomorphism of the discotic materials. A number of different methods have been used for studying the structural and orientational order in discotic liquid crystals. These are nuclear magnetic resonance (NMR) [1], X-ray [2] and infrared spectroscopy [3-5]. Despite the fact that vibrational spectroscopy is found to be very sensitive to the structure and orientational ordering of the molecules it is generally not trivial to obtain complete assignment of the fundamental frequencies in the experimental spectra. For large size molecules it is therefore necessary to determine the vibrational frequencies by computational methods and then compare them with the experimental spectra.

In the paper we calculate harmonic vibrational frequencies for triphenylene which is probably the most popular discotic mesogen and for its 2,3,6,7,10,11-alkoxy derivatives ( $\mathrm{H} n \mathrm{~T}, n=1,3,5,7)$. The hybrid B3-LYP functional is used in density 
functional theory (DFT) calculations. The experimental IR spectra of the selected compounds have been measured in the solid and the liquid phases and the fundamental frequencies assigned in comparison with the corresponding theoretical spectra.

\section{Materials and methods}

\subsection{Samples description}

The molecules used for these studies belong to the triphenylene homologous series. Figure 1 shows the structure of the triphenylene and the hexasubstituted triphenylene derivatives: 2,3,6,7,10,11-hexamethyloxy (H1T) and hexapropyloxy (H3T) triphenylene, and two discotic liquid crystals: 2,3,6,7,10,11-hexapentyloxy (H5T) and hexaheptyloxy (H7T) triphenylene. These liquid crystal (LC) molecules form nematic and columnar discotic phases. The analysis and the comparison of

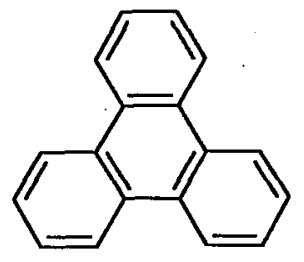

triphenylene

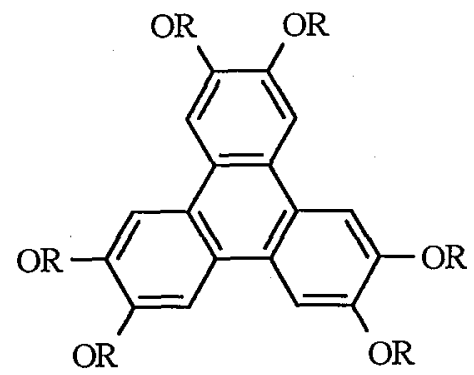

OR

$$
\begin{aligned}
& \mathrm{R}=\mathrm{CH}_{3} \\
& \mathrm{R}=\mathrm{C}_{3} \mathrm{H}_{7} \\
& \mathrm{R}=\mathrm{C}_{5} \mathrm{H}_{11} \\
& \mathrm{R}=\mathrm{C}_{7} \mathrm{H}_{15}
\end{aligned}
$$

Fig. 1. Molecular structures of investigated molecules.

the theoretical and experimental spectra for the primary compounds of this homologous series (triphenylene, $\mathrm{H} 1 \mathrm{~T}$, and $\mathrm{H3T}$ ) are helpful in a complete fundamental vibrational assignment and the detailed interpretation of vibrational spectra of large LC molecules (H5T, H7T).

\subsection{IR measurement}

The experimental spectra for the above compounds were measured in the crystalline phases using BioRad FT-IR 6000 spectrometer. The infrared spectra of triphenylene, the $\mathrm{H} 1 \mathrm{~T}$ and the $\mathrm{H} 3 \mathrm{~T}$ in the $\mathrm{KBr}$ pellets were measured in the range of 500-4000 $\mathrm{cm}^{-1}$ with the spectral resolution of $1 \mathrm{~cm}^{-1}$. Also infrared spectra of the crystalline $\mathrm{H} 5 \mathrm{~T}$ and the H7T were recorded in the same range for comparison. The LC samples were introduced into the cell by the capillary effect at the temperature a few degrees above the isotropic transition point $(\approx 395 \mathrm{~K})$. The thickness of the cell varied from 6 to $11 \mu \mathrm{m}$. The IR spectra for both were recorded in the range of $600-4000 \mathrm{~cm}^{-1}$. 


\subsection{Calculations}

All calculations in this study were performed using the 1998 Gaussian suite of program (G98W) [6]. The molecular structures, the harmonic vibrational force constants and absolute IR intensities were calculated by the B3-LYP method (the Becke three-parameter exchange functional in combination with the Lee, Yang and Parr correlation functional) $[7,8]$ with the $6-31 G^{*}$ basis set [8]. Vibrational force constants were evaluated by analytical calculations of the second derivatives of the molecular potential energy at the corresponding fully optimised geometries. The theoretical DFT force fields were transformed from Cartesian into the local internal co-ordinates using method given by Pulay et al. [9], and then scaled empirically according to the scaled quantum mechanical (SQM) procedure [9-12]:

$$
F_{i j}^{\text {scaled }}=\left(C_{i} C_{j}\right)^{1 / 2} F_{i j}^{\text {DFT }},
$$

where $C_{i}$ is the scale factor of co-ordinate $i, F_{i j}^{\mathrm{DFT}}$ is the B3-LYP/6-31G* force constant in the local internal co-ordinates, and $F_{i j}^{\text {scaled }}$ is the scaled force constant. Scaling factors in the SQM method were taken from the set of Rauhut and Pulay [12] (see Table I). The final vibrational frequencies and potential energy distributions (PEDs) were derived by Wilson's GF matrix method [13] from the SQM DFT force fields.

\section{TABLE I}

Optimised scaling factors.

\begin{tabular}{l|l}
\hline \hline \multicolumn{2}{c}{ Scaling factors } \\
\hline stretch X-X & 0.9254 \\
stretch $\mathrm{X}-\mathrm{H}$ & 0.9182 \\
bend $\mathrm{X}-\mathrm{X}-\mathrm{X}$ & 0.9923 \\
bend $\mathrm{X}-\mathrm{X}-\mathrm{H}$ & 0.9431 \\
bend $\mathrm{H}-\mathrm{X}-\mathrm{H}$ & 0.9171 \\
out-of-plane bends & 0.9711 \\
torsion conjugated & 0.9389
\end{tabular}

\section{Results and discussion}

Experimental and calculated vibrational frequencies for all the molecules are compiled in Table II. In order to improve the visual comparison between experimental and calculated IR spectra, the calculated absorption lines have been replaced by Gaussian functions with a half-width of $5 \mathrm{~cm}^{-1}$ (Figs. 2, 3, 4). The theoretical IR intensities were normalised to arbitrary units (100 for the strongest band). The harmonic force constant and frequencies are usually higher than the corresponding experimental quantities (due to the combination of electron correlation effects and limitations of the functional basic set), therefore the scaling procedure is commonly used for the theoretical frequencies set. The calculated 
TABLE II

Vibrational frequencies and assignments of triphenylene, H1T, H3T, H5T and H7T.

\begin{tabular}{|c|c|c|c|c|c|c|c|c|}
\hline \multicolumn{2}{|c|}{ Triphenylene } & \multicolumn{2}{|c|}{$\mathrm{H} 1 \mathrm{~T}$} & \multicolumn{2}{|c|}{ H3T } & \multirow{2}{*}{$\frac{\mathrm{H} 5 \mathrm{~T}}{\text { obs. }^{a}}$} & \multirow{2}{*}{$\begin{array}{r}\text { H7T } \\
\text { calc. }^{b}\end{array}$} & \multirow{3}{*}{ Assignment } \\
\hline obs. ${ }^{a}$ & calc. $^{b}$ & obs. ${ }^{a}$ & calc. $^{b}$ & obs. $^{a}$ & calc. $^{b}$ & & & \\
\hline \multicolumn{8}{|c|}{$\nu\left[\mathrm{cm}^{-1}\right]$} & \\
\hline 618 & 630 & 628 & 632 & 670 & 690 & 656 & & $\gamma \mathrm{C}_{\mathrm{Ar}}-\mathrm{C}_{\mathrm{AI}}$ \\
\hline 772 & 768 & & & & & & & \multirow{2}{*}{$\gamma \mathrm{C}_{\mathrm{Ar}}-\mathrm{H}$} \\
\hline \multirow[t]{2}{*}{779} & 775 & 779 & 776 & 770 & 778 & 768 & 775 & \\
\hline & & 834 & 836 & 827 & 823 & 824 & 822 & $\beta_{\mathrm{as}} \mathrm{CH}_{2}$ \\
\hline \multirow[t]{3}{*}{850} & 854 & 843 & 842 & 840 & 837 & 836 & 837 & $\gamma \mathrm{C}_{\mathrm{Ar}}-\mathrm{H}$ \\
\hline & & & & 862 & 867 & 864 & 865 & \multirow{2}{*}{$\nu \mathrm{CCC}$} \\
\hline & & & & 892 & 893 & 897 & 913 & \\
\hline \multirow[t]{2}{*}{994} & 993 & 971 & 972 & 964 & 973 & 980 & 970 & $\beta \mathrm{C}_{\mathrm{Ar}}-\mathrm{C}_{\mathrm{Ar}}$ \\
\hline & & 1021 & 1038 & 1035 & 1027 & 1031 & 1043 & $\nu_{\mathrm{s}} \mathrm{COC}+\nu \mathrm{CCC}$ \\
\hline 1051 & 1050 & 1049 & 1057 & 1056 & 1058 & 1056 & 1058 & \multirow{2}{*}{$\beta \mathrm{C}_{\mathrm{Ar}}-\mathrm{H}$} \\
\hline \multirow[t]{3}{*}{1062} & 1058 & 107.0 & 1068 & 1071 & 1062 & 1074 & 1069 & \\
\hline & & 1159 & 1161 & 1152 & 1149 & 1148 & 1148 & $\delta_{\mathrm{as}}^{-} \mathrm{CH}_{3}+\nu \mathrm{CCC}$ \\
\hline & & 1181 & 1182 & 1177 & 1178 & 1175 & 1173 & $\gamma_{\mathrm{as}} \mathrm{CH}_{2}+\nu_{\mathrm{as}} \mathrm{COC}$ \\
\hline \multirow[t]{3}{*}{1243} & 1244 & 1258 & 1262 & 1265 & 1264 & 1264 & 1262 & $\beta \mathrm{C}_{\mathrm{Ar}}-\mathrm{H}$ \\
\hline & & & & 1394 & 1395 & 1390 & 1387 & $\gamma_{\mathrm{s}} \mathrm{CH}_{2}$ \\
\hline & & 1419 & 1412 & & & & & $\delta_{\mathrm{as}}^{+} \mathrm{CH}_{3}$ \\
\hline \multirow[t]{2}{*}{1433} & 1436 & 1435 & 1438 & 1440 & 1444 & 1440 & 1439 & $\beta \mathrm{C}_{\mathrm{Ar}}-\mathrm{C}_{\mathrm{Ar}}$ \\
\hline & & 1465 & 1470 & 1470 & 1474 & 1468 & 1465 & $\beta_{\mathrm{as}} \mathrm{CH}_{2}$ \\
\hline 1503 & 1501 & 1521 & 1520 & 1521 & 1521 & 1517 & 1516 & \multirow{2}{*}{$\nu \mathrm{C}_{\mathrm{Ar}}-\mathrm{C}_{\mathrm{Ar}}$} \\
\hline \multirow[t]{6}{*}{1603} & 1610 & 1620 & 1615 & 1620 & 1615 & 1618 & 1616 & \\
\hline & & & & 2855 & 2861 & 2861 & 2857 & $\nu_{\mathrm{s}} \mathrm{CH}_{2}$ \\
\hline & & & & 2938 & 2943 & 2936 & 2928 & $\nu_{\mathrm{as}} \mathrm{CH}_{2}$ \\
\hline & & 2904 & 2894 & 2877 & 2897 & 2874 & 2874 & $\nu_{\mathrm{s}} \mathrm{CH}_{3}$ \\
\hline & & 2981 & 3004 & 2963 & 2969 & 2960 & 2959 & $\nu_{\mathrm{as}} \mathrm{CH}_{3}$ \\
\hline & & $\begin{array}{r}3104- \\
3118\end{array}$ & $\begin{array}{r}3108- \\
3126\end{array}$ & $\begin{array}{r}3051- \\
3103\end{array}$ & $\begin{array}{r}3049- \\
3130\end{array}$ & $\begin{array}{r}3075- \\
3110\end{array}$ & $\begin{array}{r}3074- \\
3108\end{array}$ & $\nu \mathrm{C}_{\mathrm{Ar}}-\mathrm{H}$ \\
\hline
\end{tabular}

${ }^{a}$ From IR spectra crystalline phase (see text).

${ }^{b}$ Frequencies are calculated from the scaled B3-LYP/6-31G* force field.

Key: $\nu$ - stretch, $\nu \mathrm{CCC}-$ skeletal, $\beta$ - in-plane deformation, $\gamma$ - perpendicular deformation, $\delta$ - deformation ( $\delta^{-}$-rocking), $s$, as - symmetric and asymmetric [14].

spectrum was scaled using set of seven scaling factors (see Table I). The most of the fundamentals in the range of $500-2000 \mathrm{~cm}^{-1}$ well reproduce vibrations in the experimental spectra. A number of theoretical frequencies are degenerated but they are observed as split peaks in the experimental spectra of the crystalline sample $\left(840,1210,1520 \mathrm{~cm}^{-1}\right.$ for $\left.\mathrm{H} 1 \mathrm{~T}\right)$. There are some frequencies of the neglected intensities in the theoretical spectra, but they are becoming visible in the 


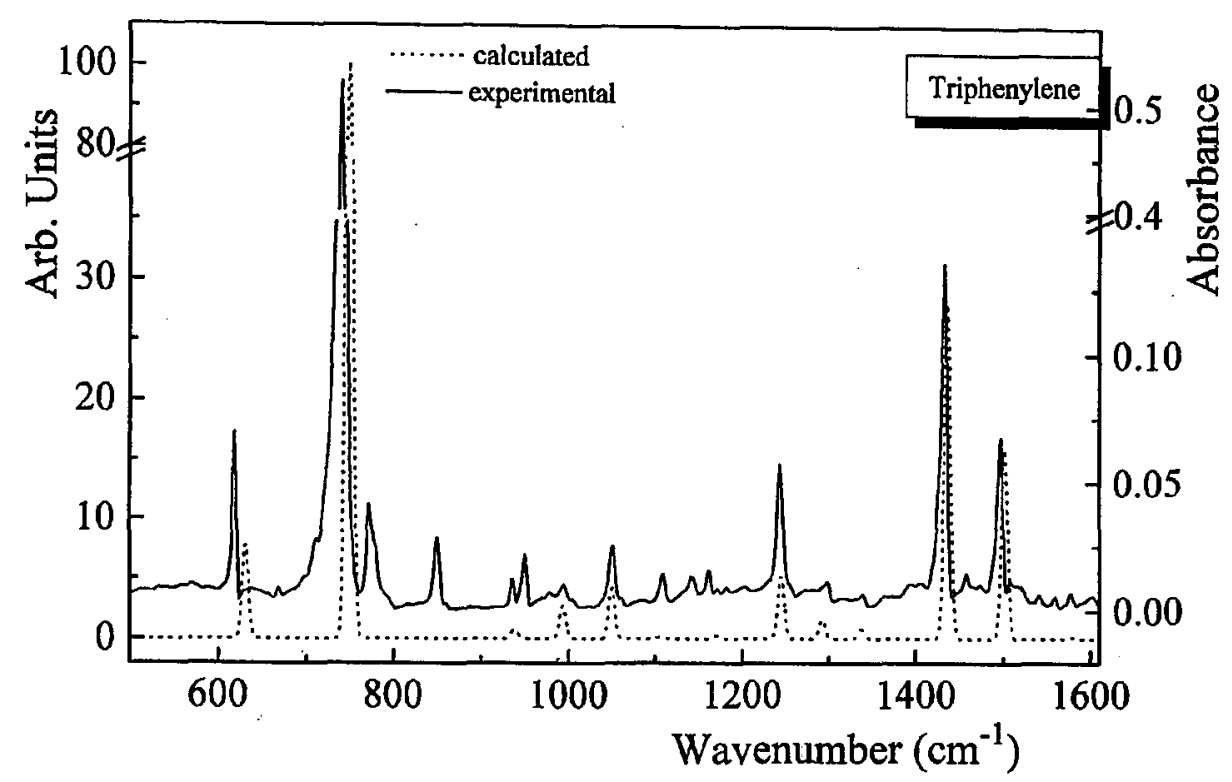

Fig. 2. Experimental and calculated (B3-LYP/6-31G*) infrared spectrum of triphenylene.

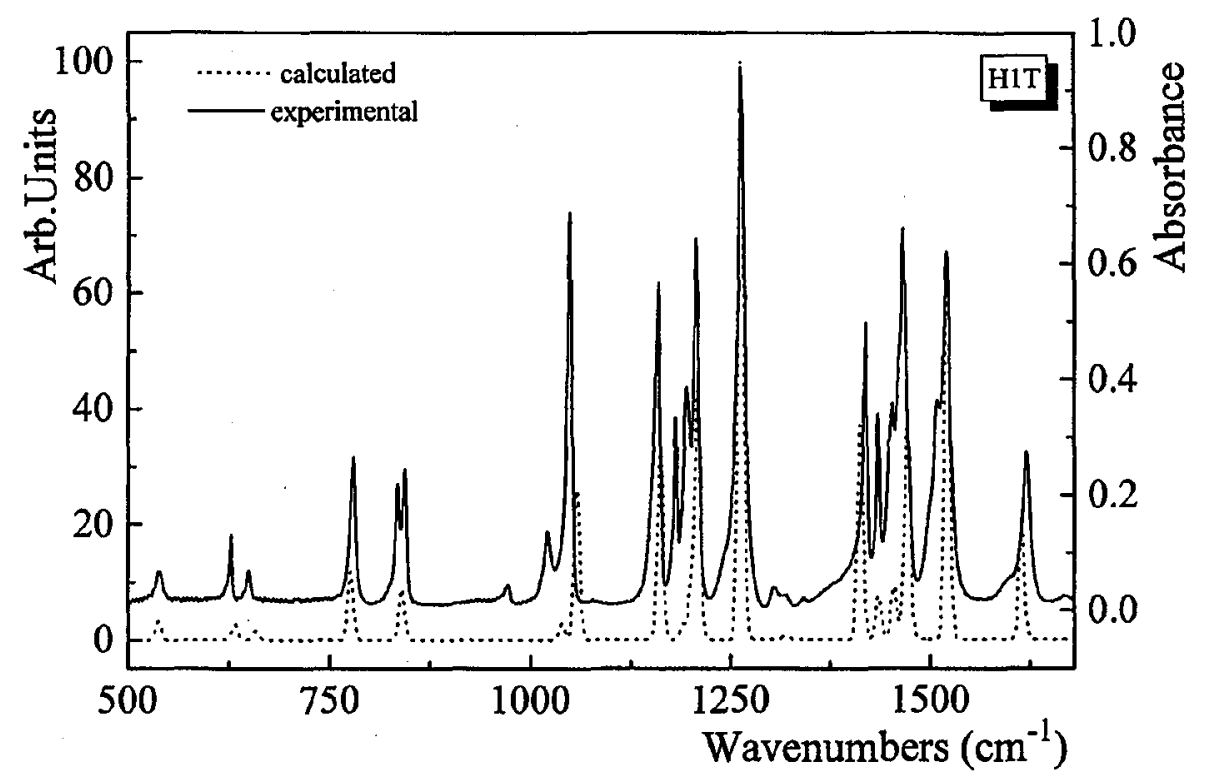

Fig. 3. Experimental and calculated (B3-LYP/6-31G*) infrared spectrum of H1T.

experiment, due to the breaking of symmetry of the molecule in the crystalline phase. The bands in the range of $2900-3100 \mathrm{~cm}^{-1}$ are not well reproduced by the 


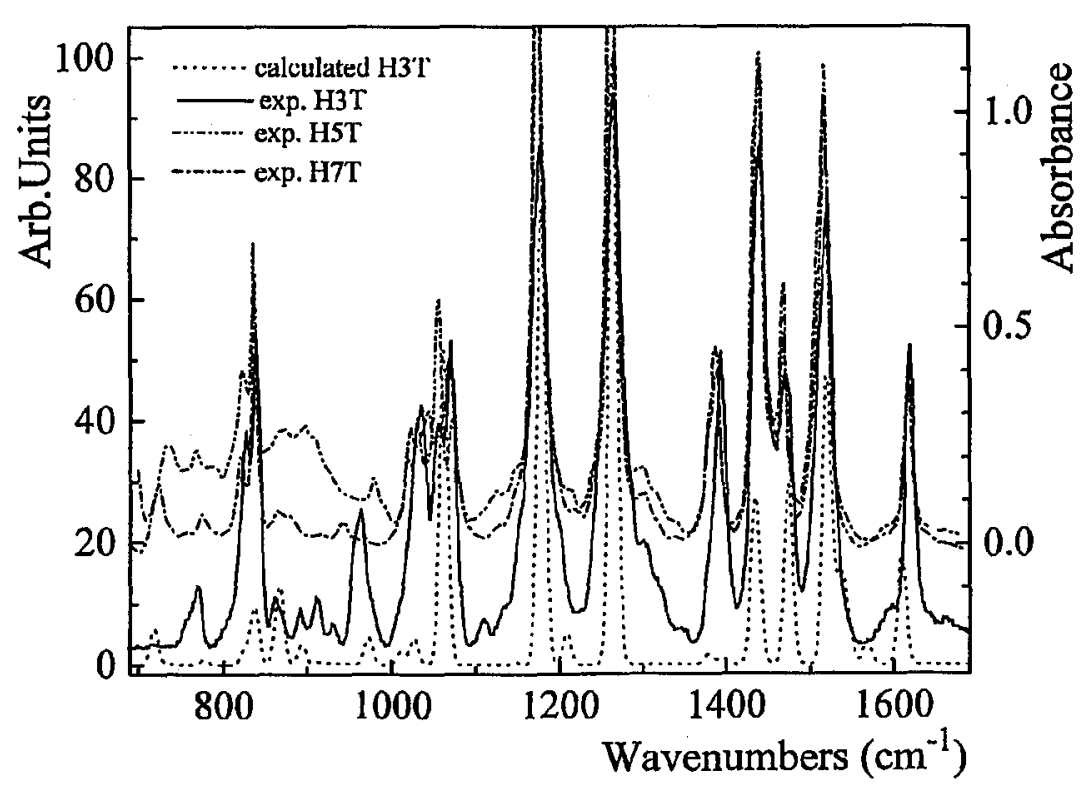

Fig. 4. The comparison of the theoretical (B3-LYP/6-31G*) and experimental spectra for the H3T, H5T and H7T molecules.

theoretical frequencies. It is due to the strong overlapping of the bands, presence of the combinational bands and the fact that the $\mathrm{C}-\mathrm{H}$ stretching frequencies are largely perturbed by the Fermi resonance effects.

Unfortunately, the H5T and H7T molecules are found to be too large for $a b$ initio calculations. Therefore only spectra calculated for H3T can be used for comparison with experimental ones of $\mathrm{H} 3 \mathrm{~T}, \mathrm{H} 5 \mathrm{~T}$ and $\mathrm{H} 7 \mathrm{~T}$ (see Fig. 4). The most apparent differences are observed in the low frequency range (below $900 \mathrm{~cm}^{-1}$ ), which may be affected by manifold of tails conformation and variation of the tail size. Nevertheless, the theoretical spectra of H3T can practically be applicable in the band assignment of the whole homologous series starting from $n=3$.

\section{Conclusion}

The molecular structure and normal force field have been calculated for triphenylene and its hexasubstitutes using the B3-LYP/6-31G* method. The usual scaling procedure of the SQM method was applied to the DFT force field. An excellent agreement between the theoretical and experimental frequencies has been observed in the range of $500-2000 \mathrm{~cm}^{-1}$. In contrast, frequencies in the range of $2900-3100 \mathrm{~cm}^{-1}$ are difficult to assign. The results indicate that the density functional theory is a reliable method of calculation of the fundamentals, and very useful in obtaining proper assignment of the experimental spectra. 


\section{Acknowledgment}

This work was partly supported by the Committee for Scientific Research under grant No. 2P03B10116.

The authors of the article thank Prof. Pulay for his Scaled Quantum Mechanical program and Mr. Jarzecki for help.

\section{References}

[1] D. Goldfarb, Z. Luz, H. Zimmermann, J. Phys. 42, 1303 (1981).

[2] A.M. Levelut, F. Hardouin, H. Gasparoux, C. Destrade, N.H. Tinh, J. Phys. 42, 147 (1981).

[3] G. Kruk, A. Kocot, R. Wrzalik, J.K. Vij, O. Karthaus, H. Ringsdorf, Liquid Crystals 14, 807 (1993).

[4] B. Orgasińska, A. Kocot, K. Merkel, R. Wrzalik, J. Zioło, T. Perova, J.K. Vij, J. Mol. Struct. 511-512, 271 (1999).

[5] B. Orgasińska, T.S. Perova, K. Merkel, A. Kocot, J.K. Vij, J. Mater. Sci. Eng. C 8-9, 293 (1999).

[6] M.J. Frish, G.W. Trucks, H.B. Schlegel, P.M.W. Gill, B.G. Johnson, M.W. Wong, J.B. Foresman, M.A. Robb, M. Head-Gordon, E.S. Replogle, R. Gomperts, J.L. Andres, K. Raghrachari, J.S. Binkley, C. Gonzalez, R.L. Martin, D.J. Fox, D.J. Detrees, J. Baker, J.J.P. Stewart, J.A. Pople, GAUSSIAN 98, A.3, Gaussian Inc., Pittsburgh (PA) 1998.

[7] A.D. Becke, Phys. Rev. A 38, 3098 (1988).

[8] J.B. Foresman, A.E. Frisch, Exploring Chemistry with Electronic Structure Methods, Gaussian Inc., Pittsburgh (USA) 1998.

[9] P. Pulay, G. Fogarasi, G. Pang, J.E. Boggs, J. Am. Chem. Soc. 101, 2550 (1979).

[10] J. Baker, A.A. Jarzecki, P. Pulay, J. Phys. Chem. A 102, 1412 (1998).

[11] Ying Xue, Daiqian Xie, Guosen Yan, Int. J. Quant. Chem. 76, 686 (1999).

[12] G. Rauhut, P. Pulay, J. Phys. Chem. 99, 3093 (1995).

[13] E.B. Wilson, J.C. Decius, P.C. Cross, Molecular Vibrations, McGraw-Hill, New York 1995.

[14] G. Varsányi, Assignments for Vibrational Spectra of 700 Benzene Derivatives, Wiley, New York 1974. 